\title{
High Performance of Matrix Converter Fed Induction Motor for IPF Compensation by Using New DSVM Method
}

\author{
Ramsagar Kola ${ }^{1}$, Tegala Srinivasa $\mathrm{Rao}^{2}, \mathrm{~K}$ durgarao ${ }^{3}$, \\ ${ }^{1}$ P.G Student Scholar, Associate Professor ${ }^{2}$, Assistant Professor ${ }^{3}$, \\ ${ }_{1,2,3}$ Department of Electrical \& Electronics Engineering \\ ${ }^{1,2,3}$ Avanti Institute of Engineering \& Technology, Makavaripalem(P), Vishakhapatnam(Dt), Andhra Pradesh, \\ India.
}

\begin{abstract}
In the matrix converter $(M C)$ system to improve the input current quality with low harmonic components, as well as to reduce the input voltage distortion supplied to the MC by using input filters. The major consequence of the paper is about the inter harmonics appearing in the induction motor drive.. In this paper, we propose a new direct space vector modulation (DSVM) method to achieve the required displacement angle between the input voltage and input current of the MC. The paper illustrates the various inter harmonics elimination methods of SVM inverter fed drive and the associated drawbacks. The drawbacks are eliminated by using New DSVM method instead of SVM method in matrix converter fed induction motor drive. A new switching strategy is introduced based on the maximum compensated angle. Then, power factor compensation algorithms using the new DSVM method to achieve the maximum IPF. In which Compensation algorithm is subsequently proposed using a proportional-integral controller to overcome drawbacks presented in compensation algorithm of SVM method. Simulation and experimental results are shown to validate the effectiveness of the proposed compensation algorithms.
\end{abstract}

Keywords: Direct space vector modulation (DSVM) method, induction motor drive, inter-harmonics, input filter, matrix converter $(M C)$.

\section{Introduction}

In the recent trends the evolution of power device technology and the development of large-power integrated circuits have revised the direct ac-ac power conversion technologies. These types of converter fulfill all requirements of conventionally used rectifier/dc link/inverter structures and provide efficient ways to convert electric power for motor drives, uninterruptible power supplies, variable-frequency generators, and reactive energy control $[1,2]$. Input filter designs for MC guarantee near-unity power factor operation on the power supply side by improving the main input current quality, which has sinusoidal waveforms containing low harmonic components, and by reducing distortion of input voltages that are supplied to the MC module [3], [4]. The presence of input filter in the direct ac-ac power conversion, which has no energy storage, can cause the instability during operations [5]-[7]. In [8] and [9], the input filter design for sliding mode controlled MC considered the maximum allowable displacement angle introduced by the filter and the controllable IPF capability, as well as the ripple presented in capacitor voltages.

In this paper, the DSVM is proposed which allows the generation of the voltage vectors required to implement the DTC of induction motor, furthermore, the input power factor is continuously controlled to be in phase with the input line-to-neutral voltage vector based on the direct SVM technique. The appropriate switching configurations of the matrix converter for each constant time are presented in an opportune switching table [10]. The table is only entered by the imaginary voltage vector, which is generated from the conventional DTC method for voltage source inverter (VSI), and the position of input voltage vector which can be measured exactly, respectively. Simulation and experiment at the high-speed and low-speed are carried out to prove the good performances of the novel method. The general block diagram of the mathematical mode of induction motor is shown in Figure 1.

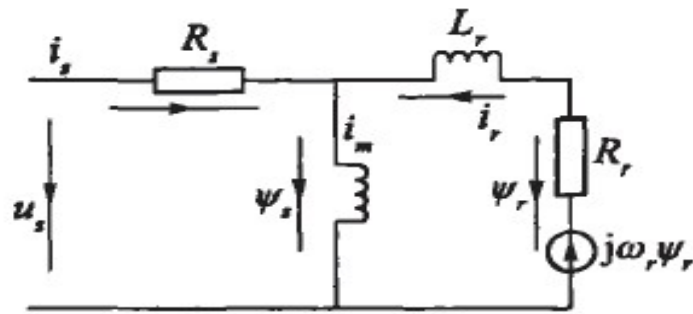

Fig 1. The mathematical mode of induction motor 
But when VFD is fed with an unbalanced load, it has both the fundamental harmonic and the inter harmonics components appearing in the voltage and current of the drive [11]-[12]. The inter harmonics originates from the load side of the drive i.e. inverter AC side. Then, on propagation through the DC link, the inter harmonics get magnified by the DC link resonance. Finally, this current appears at the AC side of the rectifier as a combination of both the supply and inverter frequencies. They also occur in the drive, when two AC systems are not properly decoupled by DC link [11, 12, and 13].

The authors in [14] proposed an integration of MC with filters that provides lower electromagnetic interference, lower common-mode current, and lower shaft voltage. However, the basic hardware limitation of the input filter still exists, which results in a displacement angle between input line-to-neutral voltage and input line current at the main power supply. Consequently, the IPF at the power supply could be far from the desired power factor of unity. In particular, in the case of low-output-power condition, the IPF at the power supply would decrease significantly. In order to overcome this problem, we proposed a new direct space vector modulation (DSVM) method based on the maximum controllable displacement angle between the input current and input voltage of the MC. The new DSVM method was developed by using a new pulse width modulation (PWM) switching pattern which authors already introduced the basic idea succinctly in [15]. In this paper, two IPF compensation algorithms using the new DSVM are proposed to improve the IPF of the MC

The proposed compensation algorithm is suggested to overcome the drawbacks presented in the first compensation algorithm. This compensation algorithm is based on a proportional-integral (PI) controller usage for power factor control. Aside from the flexible adjustment capability of the power factor that this compensation algorithm can provide, its performance is independent on the MC's hardware configuration. The results obtained are presented illustrating better performances of the proposed compensation algorithms using the new DSVM method. Furthermore, results on a 5-hp induction motor control, applying the power factor compensation algorithm based on a PI controller, are given to validate the feasibility and effectiveness of the proposed compensation algorithms for dynamic load conditions.

\subsection{Space Vectors of MC}

\section{System Design Model}

The three-phase MC module includes nine bidirectional switches, as shown in Fig. 2. There are 27 possible switching configuration (SC) states. However, only $21 \mathrm{SCs}$ of them can be used to implement the modern control algorithms for the MC such as the SVM and direct torque control methods. As shown in Table I, the following are observed.

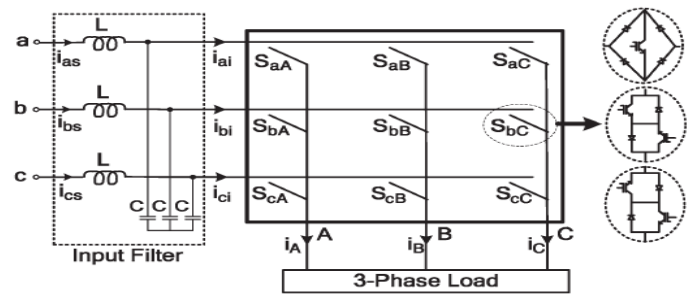

Fig. 2. Structure of a three-phase ac-ac MC.

1) Group I $( \pm 1, \pm 2, \ldots \ldots \pm 9 \square)$ consists of the SCs which have two output phases connected to the same input phase.

2) Group II $\left(0 a, 0_{b}, 0 c\right)$ consists of the SCs which have all output phases connected to a common input phase. For each SC, the corresponding line-to-neutral voltage vector and input line current vector have fixed directions as represented in Fig. 3.

3) Group III consists of six other SCs which have the output phases connected to different input phases. The output voltage vector and input current vector have variable directions and can rarely be used.

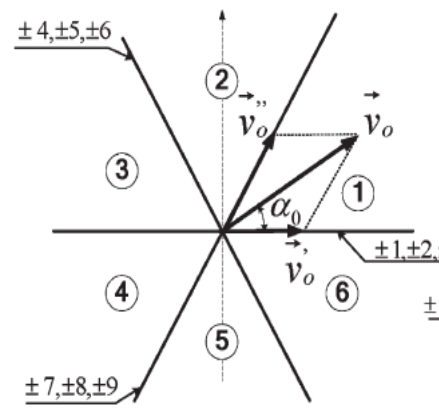

(a)

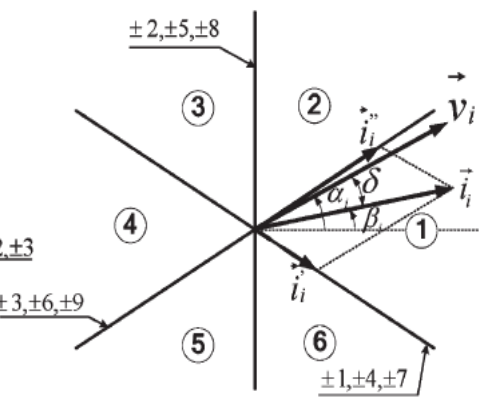

(b)

Fig. 3. (a) Output line-to-neutral voltage vector. (b) Input line current vector. 


\subsection{New DSVM Method for MC}

For the sake of explaining the new DSVM method, we assume both the desired output voltage and the input voltage space vectors to be located in sector 1 without missing the generality of the analysis $\left(0 \leq \alpha_{o} \leq \pi / 3\right.$ and $k_{v}=1,-\pi / 6 \leq \alpha_{i} \leq \pi / 6$ and $k_{i}=1$ ), as shown in Fig. 3, where $k_{v}$ and $k_{i}$ are the output voltage vector sector and the input voltage vector sector, respectively and design simulation model blocks are shown in figure 4(a), 4(b) and 4(c).

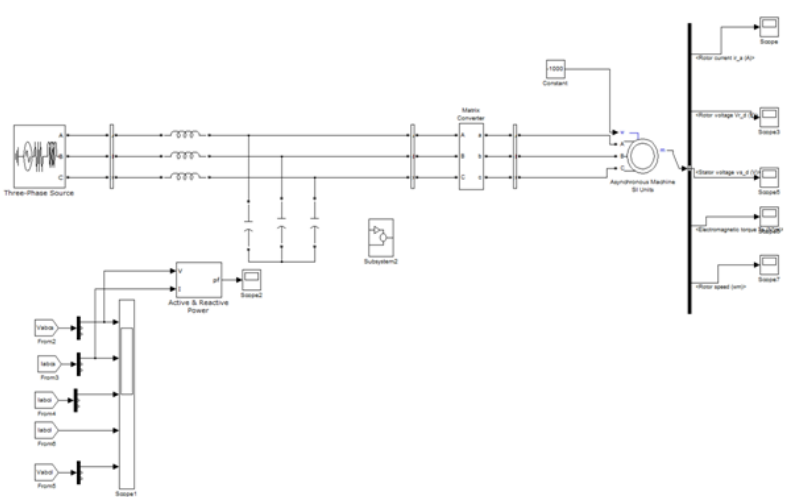

Fig. 4(a) design simulation model.

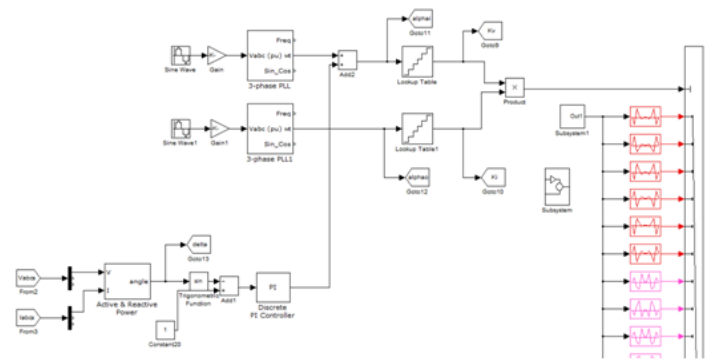

Fig. 4(b) design subsystem2 for PI controller simulation model.

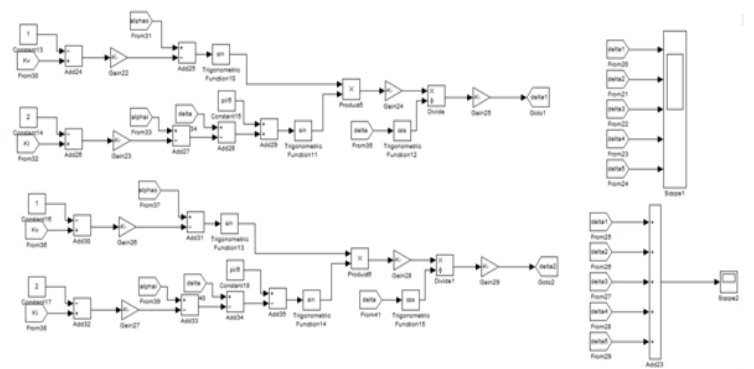

Fig. 4(c) design subsystem1 for duty cycles simulation model

Case 1: The displacement angle places the desired input current vector and the input voltage vector in the same sector $(-\pi / 6 \leq \beta i \leq \pi / 6)$ in Fig. 3(b). The desired output voltage vector $\overrightarrow{v_{0}}$ is generated from two vectors $\overrightarrow{v_{0}}$ 'and $\overrightarrow{v_{0}}$ ". To match the vector direction as $\overrightarrow{v_{0}}$ ", among the six possible SCs $(\square \pm 7, \pm 8, \pm 9)$ that have the output voltage vector in the same direction of $\overrightarrow{v_{0}}$ ", only two higher voltage magnitude vectors are considered to generate which must maintain the input current vector direction $\overrightarrow{i_{i}}$ to be inside sector 1 and lag behind the input voltage vector with a certain angle $\delta=\alpha_{i}-\beta_{i}$. In order to approach the given conditions, SCs -7 and +9 are selected to drive the MC, and from Fig. 3, the duty ratios of SCs $-7(d 1)$ and $+9(d 2)$ should satisfy the following relationship:

$$
\begin{gathered}
\frac{d_{1}}{\sin \left(\frac{\pi}{6}-\beta_{i}\right)}=\frac{d_{2}}{\sin \left(\frac{\pi}{6}+\beta_{i}\right)} \\
d_{1}\left(-2 v_{a b} / 3\right)+d_{2}\left(2 v_{c a} / 3\right)=v_{0}^{\prime \prime}
\end{gathered}
$$

Solving under the given condition $\delta=\alpha_{i}-\beta_{i}$, the duty ratios for SCs -7 and +9 are respectively as follows:

$$
\begin{aligned}
d_{1} & =\frac{2 q \sin \left[\alpha_{0}-\left(k_{v}-1\right) \frac{\pi}{3}\right] \sin \left[\frac{\pi}{6}-\left(\alpha_{i}-\delta-\left(k_{i}-1\right) \frac{\pi}{3}\right)\right]}{\sqrt{3} \cos (\delta)} \\
d_{2} & =\frac{2 q \sin \left[\alpha_{0}-\left(k_{v}-1\right) \frac{\pi}{3}\right] \sin \left[\frac{\pi}{6}+\left(\alpha_{i}-\delta-\left(k_{i}-1\right) \frac{\pi}{3}\right)\right]}{\sqrt{3} \cos (\delta)}
\end{aligned}
$$

By similar analysis, the SCs selected to obtain $\overrightarrow{v_{0}}$ are $+1(d 3)$ and $-3(d 4)$ with the following duty ratios: 


$$
\begin{gathered}
d_{3}=\frac{2 q \sin \left[k_{v} \frac{\pi}{3}-\alpha_{0}\right] \sin \left[\frac{\pi}{6}-\left(\alpha_{i}-\delta-\left(k_{i}-1\right) \frac{\pi}{3}\right)\right]}{\sqrt{3} \cos (\delta)} \\
d_{4}=\frac{2 q \sin \left[k_{v} \frac{\pi}{3}-\alpha_{0}\right] \sin \left[\frac{\pi}{6}+\left(\alpha_{i}-\delta-\left(k_{i}-1\right) \frac{\pi}{3}\right)\right]}{\sqrt{3} \cos (\delta)}
\end{gathered}
$$

Finally, zero SC $(d 5)$ is applied to complete the sampling period

$$
\begin{aligned}
& \mathrm{d}_{5}=1-\left(\mathrm{d}_{1}+\mathrm{d}_{2}+\mathrm{d}_{3}+\mathrm{d}_{4}\right) \\
& =\frac{2 q \cos \left[\alpha_{0}-\frac{\left(2 k_{v}-1\right) \pi}{6}\right] \cos \left[\alpha_{i}-\delta-\frac{\left(k_{i}-1\right) \pi}{3}\right]}{\sqrt{3} \cos (\delta)}
\end{aligned}
$$

where $d 1, d 2, d 3, d 4$, and $d 5$ are the duty ratios of four active SCs (in this case, $-7,+9,+1$, and -3 ) and zero $\mathrm{SC}$, respectively, and $q=v_{o} / v_{m}$ is the voltage transfer ratio. Table II shows all switching patterns that can be used in the DSVM method if the desired input current vector is located in the same sector with the input voltage vector.

Case 2: The displacement angle places the desired input current vector and input voltage vector in different sectors. Without missing the generality of the analysis, we assume that the input voltage vector is located in sector $1(-\pi / 6 \leq \alpha i \leq \pi / 6)$ and that the desired input current vector is located in sector $6(-\pi / 2 \leq \beta i \leq-\pi / 6)$ with the different phase angle $\delta$ shown in Fig. 5 .

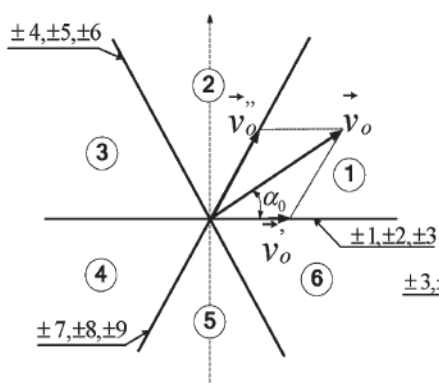

(a)

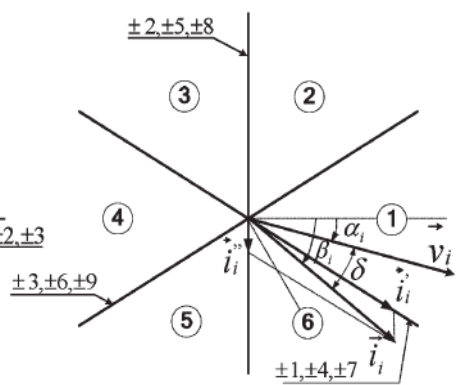

(b)

Fig. 5. (a) Output line-to-neutral voltage vector. (b) Input current and voltage vectors at different sectors.

Similar to Case 1 , to generate the desired voltage vector $\overrightarrow{v_{0}}$ and to maintain the desired different phase angle $\delta$ between the input current vector and the input voltage vector, the suitable SCs selected are $-7,+8,+1,-2$, and zero SCs with the following duty ratios:

$$
\begin{gathered}
d_{1}=\frac{2 q \sin \left[\alpha_{0}-\left(k_{v}-1\right) \frac{\pi}{3}\right] \sin \left[\frac{\pi}{6}+\left(\alpha_{i}-\delta-\left(k_{i}-2\right) \frac{\pi}{3}\right)\right]}{\sqrt{3} \cos (\delta)} \\
d_{2}=\frac{2 q \sin \left[\alpha_{0}-\left(k_{v}-1\right) \frac{\pi}{3}\right] \sin \left[\frac{\pi}{6}-\left(\alpha_{i}-\delta-\left(k_{i}-2\right) \frac{\pi}{3}\right)\right]}{\sqrt{3} \cos (\delta)} \\
d_{3}=\frac{2 q \sin \left[k_{v} \frac{\pi}{3}-\alpha_{0}\right] \sin \left[\frac{\pi}{6}+\left(\alpha_{i}-\delta-\left(k_{i}-2\right) \frac{\pi}{3}\right)\right]}{\sqrt{3} \cos (\delta)} \\
d_{4}=\frac{2 q \sin \left[k_{v} \frac{\pi}{3}-\alpha_{0}\right] \sin \left[\frac{\pi}{6}-\left(\alpha_{i}-\delta-\left(k_{i}-2\right) \frac{\pi}{3}\right)\right]}{\sqrt{3} \cos (\delta)} \\
d_{5}=1-\frac{2 q \cos \left[\alpha_{0}-\frac{\left(2 k_{v}-1\right) \pi}{6}\right] \cos \left[\alpha_{i}-\delta-\frac{\left(k_{i}-2\right) \pi}{3}\right]}{\sqrt{3} \cos (\delta)}
\end{gathered}
$$

Where $d 1, d 2, d 3, d 4$, and $d 5$ are the duty ratios of four active SCs (in this case, $-7,+8,+1$, and -2 ) and zero $\mathrm{SC}$, respectively.

\subsection{Induction motor drive}

$\mathrm{AC}$ induction motors, which contain a cage, are very popular in variable-speed drives. They are simple, rugged, inexpensive and available at all power ratings. Progress in the field of power electronics and microelectronics enables the application of induction motors for high-performance drives, where traditionally only DC motors were applied. The AC induction motor is a rotating electric machine designed to operate from a 3 -phase source of alternating voltage. For variable speed drives, the source is normally an inverter that uses power switches to produce approximately sinusoidal voltages and currents of controllable magnitude and frequency. 


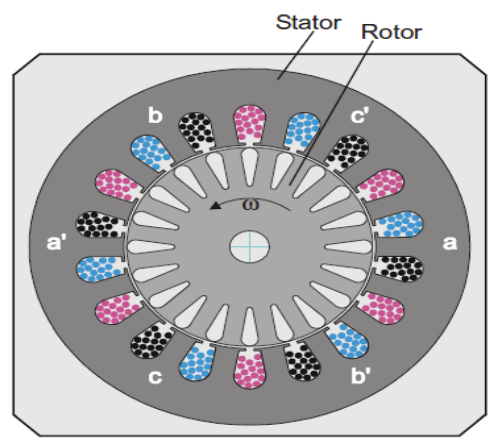

Fig.6 AC Induction motor.

A cross-section of a two-pole induction motor is shown in Figure 6. Slots in the inner periphery of the stator accommodate 3-phase winding a,b,c. The turns in each winding are distributed so that a current in a stator winding produces an approximately sinusoidally-distributed flux density around the periphery of the air gap. When three currents that are sinusoidally varying in time, but displaced in phase by $120^{\circ}$ from each other, flow through the three symmetrically-placed windings, a radially-directed air gap flux density is produced that is also sinusoidally distributed around the gap and rotates at an angular velocity equal to the angular frequency, $\omega s$, of the stator currents. The most common type of induction motor has a squirrel cage rotor in which aluminum conductors or bars are cast into slots in the outer periphery of the rotor. These conductors or bars are shorted together at both ends of the rotor by cast aluminum end rings, which also can be shaped to act as fans. In larger induction motors, copper or copper-alloy bars are used to fabricate the rotor cage winding.

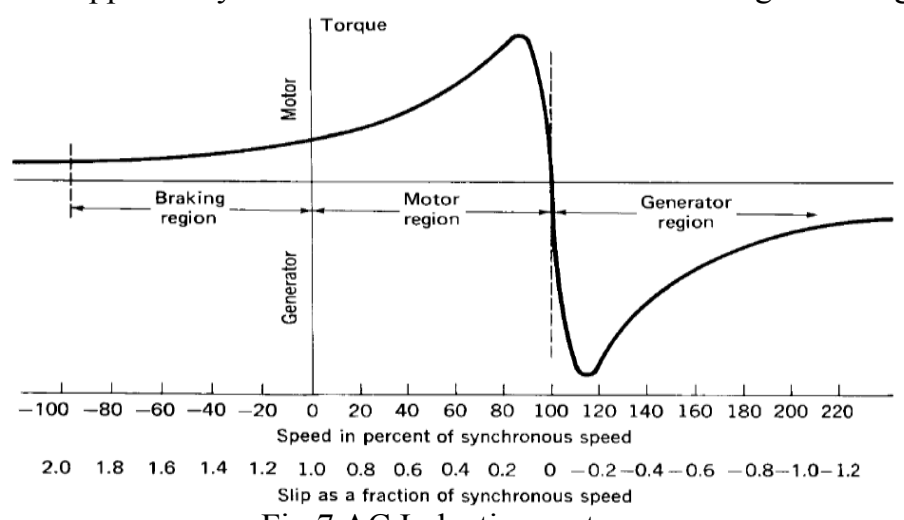

Fig.7 AC Induction motor.

The result is a sinusoidally-distributed set of currents in the short-circuited rotor bars. Because of the low resistance of these shorted bars, only a small relative angular velocity, $\omega r$, between the angular velocity, $\omega s$, of the flux wave and the mechanical angular velocity $\omega$ of the two-pole rotor is required to produce the necessary rotor current. The relative angular velocity, wr, is called the slip velocity. The interaction of the sinusoidallydistributed air gap flux density and induced rotor currents produces a torque on the rotor. The typical induction motor speed-torque characteristic is shown in Figure 7.

\subsection{Maximum Compensated Angle}

The duty ratio of the zero SC has to be positive to validate the DSVM method. Considering the fact that $d_{5} \geq 0$, we obtain

$$
q \leq \frac{\sqrt{3}}{2} \cos (\delta)
$$

The maximum voltage transfer ratio is inferred to be $\sqrt{3} \cos (\delta) / 2$, and the well-known maximum voltage transfer ratio becomes $\sqrt{3} / 2$ at $\delta=0$. As seen from (20), corresponding to each voltage transfer ratio $q$, there exist a possible maximum compensated displacement angle between the desired input current vector and the input voltage vector. However, the new DSVM method is only validated if the input voltage vector leads the input current vector to one sector, i.e., $\delta \leq \pi / 3$. The maximum compensated angle is given by

$$
\delta_{\max }=\left[\begin{array}{ll}
\cos ^{-1}\left(\frac{2 q}{\sqrt{3}}\right), & \frac{\sqrt{3}}{4} \leq q \leq \frac{\sqrt{3}}{2} \\
\frac{\pi}{3}, & 0<q \leq \frac{\sqrt{3}}{4}
\end{array}\right.
$$




\section{Simulation Results}

Simulation was carried out on a three-phase $R L$ load using MATLAB 7.9 software. The simulation parameters for the $R L$ load were as follows:1) power supply (line-to-neutral voltage): $100 \mathrm{~V} / 60 \mathrm{~Hz}$; 2) threephase $R L$ load: $26 \Omega, 12 \mathrm{mH}$. In order to determine the differences between the conventional DSVM method and our new DSVM method, the same reference output voltage was applied using compensation algorithm shown in Fig. 8. Due to the optimal compensated angle achieved by the PI controller, the main input current at the power supply is in phase with the line-to-neutral input voltage, while the MC satisfies the reference output voltage presented in the figure by the output currents and line-to-line output voltage.

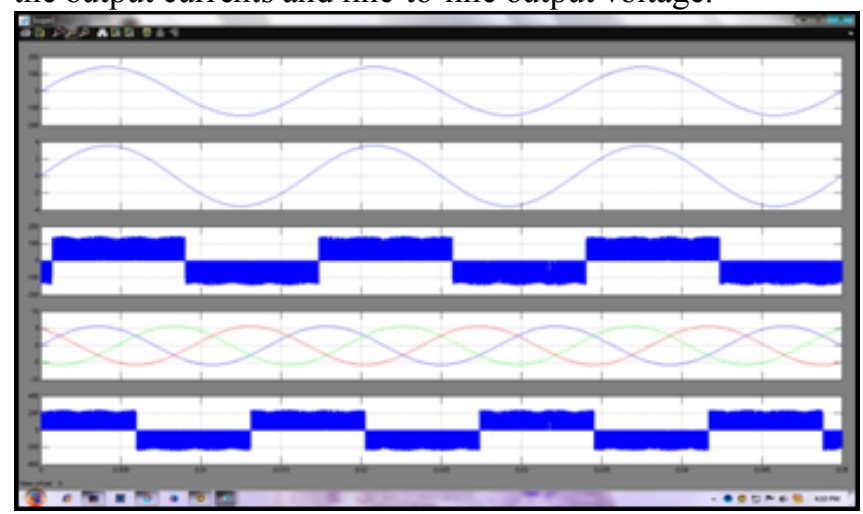

Fig. 8. Input/output waveforms of the $\mathrm{MC}$ at reference output voltage $q=0.7, f_{o}=70 \mathrm{~Hz}$ with compensation algorithm $(p f=1.0)$.

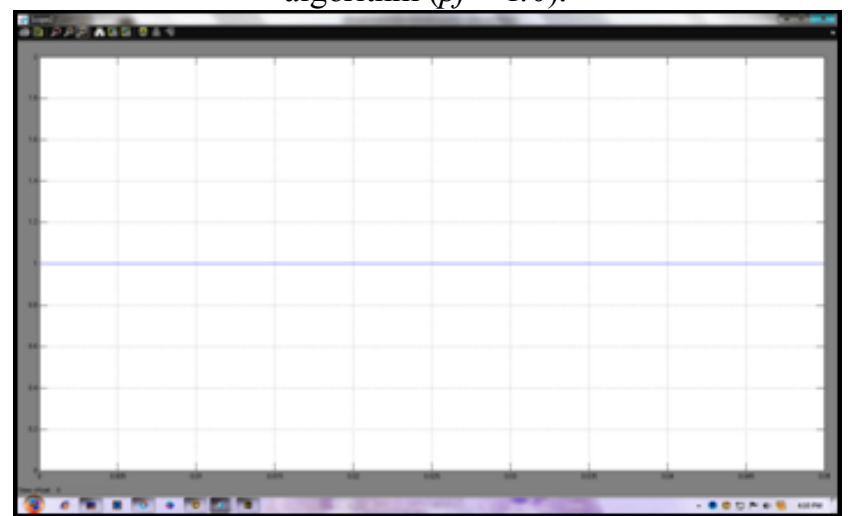

Fig.9. Power factor of the MC fed induction motor at reference output voltage $q=0.7, f o=70 \mathrm{~Hz}$ with compensation algorithm.

Our new DSVM method was applied to induction motor control to validate the effectiveness of the compensation algorithm, and in this case, compensation algorithm was examined in the experiment. The indirect field-oriented control method in combination with the new DSVM method for MC was implemented on the same MC hardware design to control a 5-hp induction motor as shown in the figure 9 and remaining figure10,figure11 are represents the subsystems simulations.

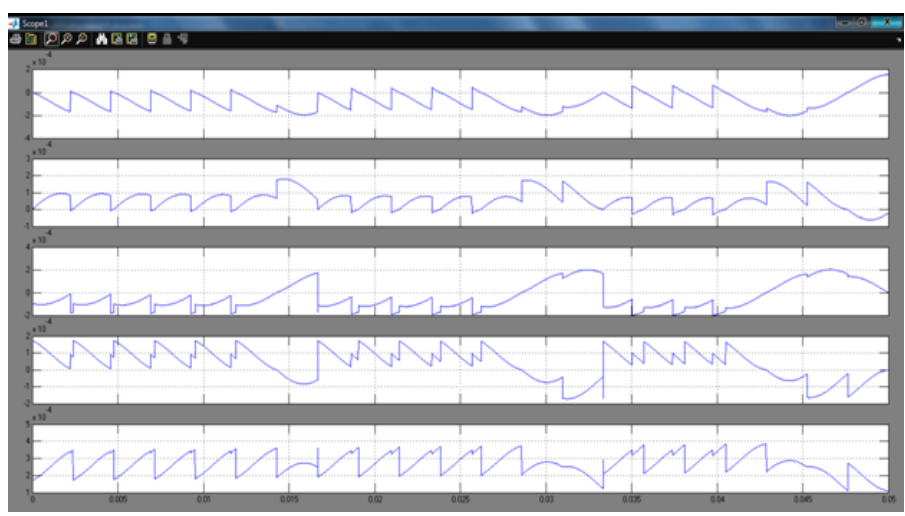

Fig.10 Sub-system 2 simulation output 


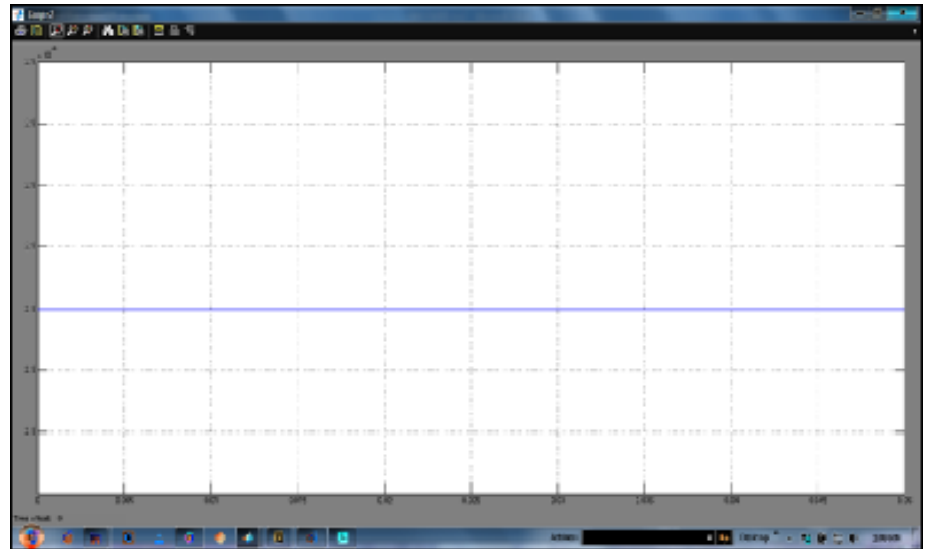

Fig.11 Sub-system 1 simulation output

\section{Conclusion}

The operational principle of the new DSVM method was presented based on the analyses of the maximum allowable compensated angle, and a new PWM switching pattern was also introduced. The new DSVM method was realized by the proposed IPF compensation algorithm. In addition to the high input power region being enlarged significantly, the smaller input current magnitude was obtained by utilizing the minimum reactive power supply. The drive could not restrict the inter harmonics to a safer limit by the conventional elimination methods like varying the $\mathrm{AC}$ side inductance and DC link resistance due to the presence of DC link. The steady-state and transient responses of the proposed algorithms were tested through simulation using the three-phase $R L$ load model

\section{References}

[1] T.F.Podlesak, D.C.Katsis, P.W.Wheeler, J.C. Clare, L.Empringham, and M.Bland "A 150-kVA vector-controlled matrix converter induction motor drive," IEEE Trans. Ind. Appl., vol. 41, no. 3, pp. 841-847, May/Jun. 2005

[2] C.Klumpner, P.Nielsen, I.Boldea, and F.Blaabjerg, "A new matrix converter motor (MCM) for industry applications," IEEE Trans. Ind. Electron., vol. 49, no. 2, pp. 325-335, Apr. 2002.

[3] P.W. Wheeler, H.Zhang, and D.A. Grant, "A theoretical, and practical consideration of optimised input filter design for a low loss matrix converter," in Proc. 9th Int. Conf. Electromagn. Compat., Sep. 1994, pp. 138-142.

[4] P.Wheeler and D.Grant, "Optimized input filter design, and low-loss switching techniques for a practical matrix converter," Proc. Inst. Elect. Eng.-Elect. Power Appl., vol. 144, no. 1, pp. 53-60, Jan. 1997.

[5] D.Casadei, G.Serra, A.Tani, and L.Zarri, "Stability analysis of electrical drives fed by matrix converters," in Proc. IEEE ISIE, Jul. 2002, vol. 4, pp. 1108-1113.

[6] D.Casadei, J.Clare, L.Empringham, G. Serra, A. Tani, P. W. Wheeler, and L. Zarri, "Large-signal model for the stability analysis of matrix converters," IEEE Trans. Ind. Electron., vol. 54, no. 2, pp. 939-950, Apr. 2007.

[7] J. Wang and M. Bouazdia, "Influence of filter parameters/topologies on stability of matrix converter-fed permanent magnet brushless motor drive systems," in Proc. IEEE Int. Elect. Machines and Drives Conf.,May 2009, pp. 964-970.

[8] S. F. Pinto and J. F. Silva, "Input filter design for sliding mode controlled matrix converters," in Proc. 32nd IEEE

[9] S.F. Pinto and J.F. Silva, "Direct control method for matrix converters with input power factor regulation," in Proc. 35th IEEE Power Electron. Spec. Conf., Jun. 2004, vol. 3, pp. 2366-2372.

[10] Duro Basic “ Input current inter-harmonics in variable speed drives due to motor current imbalance”, IEEE Transaction on Power Delivery Vol. 25, No. 4, Oct 2010.

[11] R.Yacamini, "Power system harmonics, part 4 inter-harmonics", Power Eng. J., pp. 185-193, Aug. 1996, Tutorial.

[12] F.De Rosa, R.Langella, A.Sollazzo, and A.Testa, "On the inter-harmonic components generated by adjustable speed drives," IEEE Transaction on Power Delivery, Vol. 20, No. 4, pp. 2535-2543, Oct. 2005.

[13] K.Yamada, T.Higuchi, E.Yamamoto, H.Hara, T.Sawa, M.M.Swamy, and T.Kume, "Filtering techniques for matrix converters to achieve environmentally harmonics drives," in Proc. 11th EPE, Dresden, Germany, 2005.

[14] H.H.Lee, H.M.Nguyen, and T.-W. Chun, "New direct-SVM method for matrix converter with main input power factor compensation," in Proc. 34th IEEE IECON, Nov. 10-13, 2008, pp. 281-1286. 